\title{
Enhancement of Corrosion Resistance of NiCrFeBSi Coatings Obtained by Flame Thermal Spray Process Adding an Electroless Nickel Coating Ni-P
}

\author{
Arturo Barba-Pingarrón', Raúl Valdez-Navarro1, Félix Sánchez-De Jesus²,

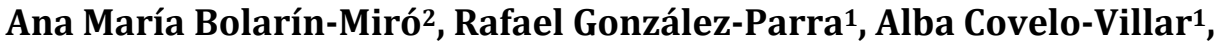 \\ Miguel Ángel Hernández-Gallegos ${ }^{1}$, Carlos Domínguez-Ríos ${ }^{3}$
}

${ }^{1}$ Centro de Ingeniería de Superficies y Acabados (CENISA), Facultad de Ingeniería, Universidad Nacional Autónoma de México, 2 Nivel Edificio “T” (Bernardo Quintana), Circuito Exterior, Ciudad Universitaria, Ciudad de México, México

${ }^{2}$ Área Académica de Ciencias de la Tierra y Materiales, Universidad Autónoma del Estado de Hidalgo, Pachuca, México ${ }^{3}$ Centro de Investigación en Materiales Avanzados, Chihuahua, México

Email: arbapin5@gmail.com, raulgvaldez@hotmail.com,rafael.parra@yandex.com, acovelov@gmail.com,mahg22@yahoo.com, abolarin@uaeh.edu.mx,fsanchez@uaeh.edu.mx, carlos.dominguez@cimav.edu.mx

How to cite this paper: Barba-Pingarrón, A., Valdez-Navarro, R., Sánchez-De Jesus, F., Bolarín-Miró, A.M., González-Parra, R., Covelo-Villar, A., Hernández-Gallegos, M.A. and Domínguez-Ríos, C. (2017) Enhancement of Corrosion Resistance of NiCrFeBSi Coatings Obtained by Flame Thermal Spray Process Adding an Electroless Nickel Coating Ni-P. Journal of Surface Engineered Materials and Advanced Technology, 7, 86-97.

https://doi.org/10.4236/jsemat.2017.74008

Received: July 21, 2017

Accepted: October 28, 2017

Published: October 31, 2017

Copyright $\odot 2017$ by authors and Scientific Research Publishing Inc. This work is licensed under the Creative Commons Attribution International License (CC BY 4.0).

http://creativecommons.org/licenses/by/4.0/

\begin{abstract}
Flame Thermal Spray (FTS) coatings frequently show some porosity and reduced adherence to substrate, which affect its properties, especially its corrosion resistance. In this work, the corrosion resistance of AISI 1018 carbon steel coated by different methods is compared: electroless nickel (EN) coating, $\mathrm{NiCrFeBSi}$ obtained by FTS, duplex coatings of an EN deposit on a layer of $\mathrm{NiCrFeBSi}$ obtained by FTS and a layer of NiCrFeBSi on an EN deposit. The coatings were characterized using optical microscopy and scanning electron microscopy techniques, EDS microprobe microanalysis, roughness as well as electrochemical polarization tests to obtain the corrosion rate. The results show the enhancement in the corrosion resistance in saline medium of the duplex coatings, especially of the EN coating on FTS layer.
\end{abstract}

\section{Keywords}

Flame Thermal Spray Coatings, Electroless Nickel Plating, Duplex Coatings, Corrosion Resistance

\section{Introduction}

Thermal spray processes include a broad group of technologies. Their usefulness 
in different areas of engineering are broad and their use has been increasing in different countries. One of the techniques that can be employed is the one called flame thermal spraying (FTS), the heat source is a mixture of oxygen-acetylene and coatings are produced by means of a gun in which the melted or heated materials are projected onto a substrate using a gas stream. With this technology, it is possible to obtain coatings with compositions comprising combinations of metals, ceramics and various polymers and composites [1]. The equipment used for this purpose is, among the available options in thermal spraying, the cheapest. However, it is often found that coatings obtained do not exhibit the desired degree of adhesion to the substrate and it is common for them to show some significant degrees of porosity. Because of that, in many cases, the development of better coatings that improve the corrosion resistance of the substrate has been an ongoing work.

Therefore, for this type of coatings, a concern is to find ways to reduce this problem and some actions have been recommended, such as applying a sealing operation of pores, in which several techniques have been used; for example, using steam or an appropriate post thermal spraying heat treatment. Other options reported are the re-melt and re-solidifying of the coatings using concentrated energy sources, such as laser radiation [2], which has improved both limitations (porosity and adhesion), and improvements in wear resistance have been reported.

Another strategy to improve the properties of the coatings, is by combining the processes of thermal spray with other surface engineering technologies, such as Physical Vapor Deposition or nitriding [3] [4] [5].

On the other hand, electroless nickel phosphorus (NiP) coatings are obtained through the chemical reduction of nickel ions, which are in aqueous solution, by the action of sodium hypophosphite without the use of electricity. This auto-catalytic chemical technique has some advantages over the electrolytic coatings, highlighting the uniformity of the coating thickness, regardless of the geometry of electroless nickel-plated parts, also depending on the phosphorous content (which, in turn, depends on the $\mathrm{pH}$ of the solution), it could be an amorphous or crystalline state [6], with an excellent corrosion resistance.

Using the electroless nickel technology it is possible to obtain different kind of coatings, modifying the methodology to apply it or the elements used. For example, adding a third element to the Ni-P alloy [7] or hard ceramic particles, such as SiC or WC [8] [9]. An additional option is the use of an electroless nickel deposit as an intermediate layer, a work using this method was reported, and the results indicate an improvement in the corrosion resistance [10]. In addition, a thin layer of electroless nickel can be placed as an intermediate coating with a $\mathrm{Cr}_{3} \mathrm{C}_{2}-\mathrm{NiCr}$ compound obtained by plasma thermal spraying, it is reported an improvement in the tribological coating behavior [11].

Duplex electroless nickel coatings $(\mathrm{NiB} / \mathrm{NiP})$ have also been produced, in order to achieve a wear and corrosion resistant coating with encouraging results 
[12] [13]. Also reported is the use of electroless nickel coated ceramic powders, on which coatings obtained by thermal spray layers are placed, resulting in an improved wear resistance [14] [15].

There are several studies about duplex coatings using thermal spray technologies; there is no study thus far on the effect of using electroless nickel plating together flame thermal spray. The goal of thiswork is to achieve a study about the effect of a kind of duplex coatings in the corrosion resistance of low carbon steel.

\section{Materials and Methods}

AISI 1018 carbon steel specimens with a dimension of $30 \times 23 \times 9.5 \mathrm{~mm}$ were used as the substrates. Surface pretreatment method includes both mechanical and chemical cleaning. Some of the pretreated specimens were electroless nickel plated using the experimental conditions previously reported [9].

The roughness of samples was obtained using a Mitutoyo Surftest 402; measures were made in 5 different zones of the pieces after they had been shot blasting with aluminum oxide particles, to ensure an appropriate level of roughness that allows adequate adhesion of the $\mathrm{NiCrFeBSi}$ layer generated by flame thermal spray process. The average roughness obtained was 19.85 micrometers.

Flame thermal spray coatings were produced using a Sulzer Metco 5P II gun, at pressure of $180 \mathrm{psi}$. The samples were preheated to $180^{\circ} \mathrm{C}$ and thermally projected for 30 seconds, with a powder combination $\mathrm{NiCr}_{10} \mathrm{Fe}_{2.5} \mathrm{~B}_{2.5} \mathrm{Si}_{2.5}$ placed in the gun, at a distance of 25 to $35 \mathrm{~cm}$.

The samples coated were observed in a Nikon 039268 metallographic microscope and a Philips XL20 scanning electron microscope. An EDS microprobe, was used for the microanalysis of the various coatings evaluated.

Other specimens, $3 \mathrm{~cm}$ in length, $2.3 \mathrm{~cm}$ wide and $1 \mathrm{~cm}$ thick were prepared for the electrochemical polarization tests, in which an AC Instruments $802 \mathrm{ACM}$ Gill potentiostat was used. A high purity graphite bar was used as the auxiliary electrode and a saturated calomel electrode $\left(\mathrm{Hg} / \mathrm{Hg}_{2} \mathrm{Cl}_{2}\right.$, sat. $\left.\mathrm{KCl}\right)$ was used as the reference electrode in a $3.5 \%$ by weight sodium chloride solution. Ten samples from five different types of systems were evaluated (Table 1). Samples were evaluated for 10 days.

In order to obtain the corrosion rate $\left(V_{\text {corr }}\right)$ the next formula was used and the parameter employed were, $I_{\text {corr }}$ refers to the corrosion current of the system, $A$

Table 1. Description of systems of samples evaluated.

\begin{tabular}{cr}
\hline Name & Designation \\
\hline Electroless Nickel on 1018 Carbon steel & CS (2) \\
Flame Thermal Spray on 1018 Carbon Steel & EN on CS (2) \\
Flame Thermal Spray plus Electroless Nickel on 1018 Carbon Steel & FTS on CS (2) \\
Electroless Nickel plus Flame Thermal Spray on 1018 Carbon Steel & EN + FTS on CS (2) \\
\hline
\end{tabular}


is the exposed surface area to the electrolyte, $\rho_{N i}$ is the density of nickel and $W_{N i}$ the molecular weight of nickel.

$$
V_{\text {corr }}=\left(\frac{I_{\text {corr }} W_{N i}}{A \rho_{N i}}\right)\left(\frac{0.5}{96,500}\right)(10)(31,536,000)
$$

\section{Results}

Figure 1 obtained by scanning electron microscopy (SEM), shows a NiCrFeBSi coating generated by flame thermal spray technology on AISI 1018 steel. Some defects can be highlighted like the inhomogeneity of the thickness, the presence of porosity and the fact that certain areas remains uncoated, where the presence of porosity and non covered areas are related with the low speed through which the molten particles travel in the processes of flame thermal spray process, which causes a limited adhesion.

Figure 2 shows an electroless nickel deposit on AISI 1018 carbon steel, where

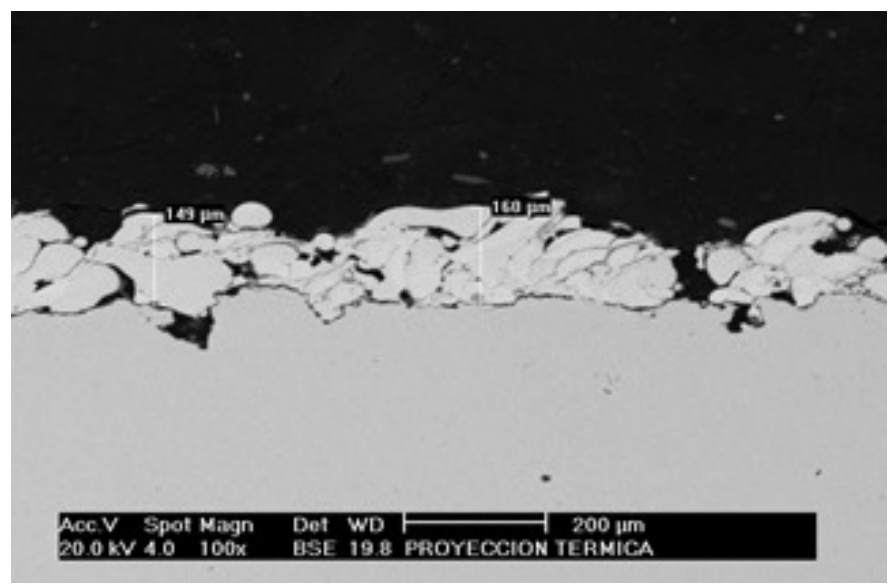

Figure 1. SEM image of NiCrFeBSi coating on AISI 1018 carbon steel obtained employingflame thermal spraying (FTS) process. It is clear the irregularity of thickness and porosity of the coating. Backscattering electrons (BSE). 100×.

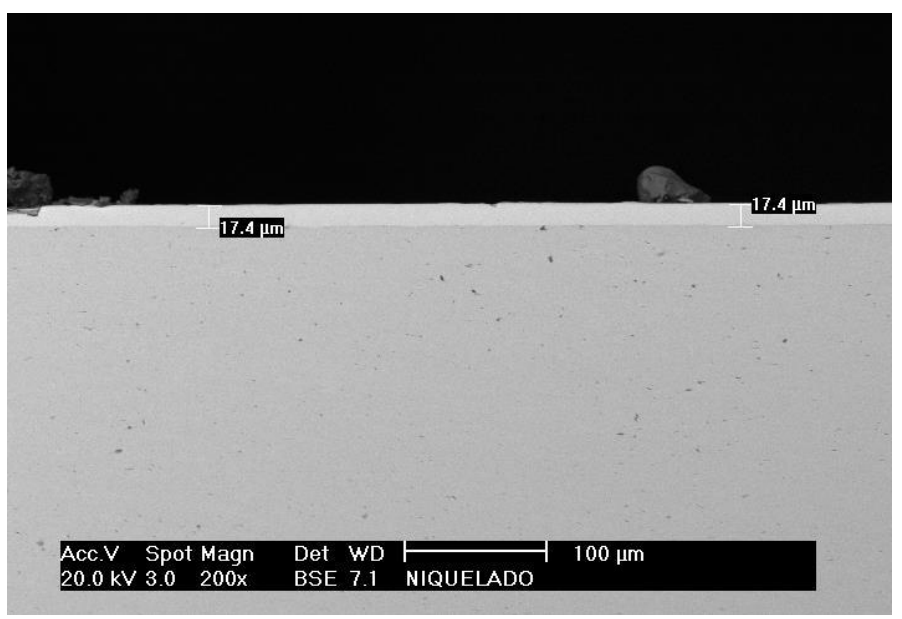

Figure 2. SEM Image of electroless Ni-P deposit on AISI 1018 steel. Is evident the uniform thickness and good adhesion to the steel substrate. BSE. $200 \times$. 
we can observe the uniformity in the thickness of the coating and good adhesion to the substrate.

Referring to Figure 3, the image of a duplex coating, consisting of an electroless nickel coating on which a layer of a $\mathrm{NiCrFeBSi}$ combination is placed, can be seen.

Some areas where the flame thermal spray layer is not able to cover the electroless nickel deposit are observed, which, as will be discussed later, is related to the inadequate behavior of this duplex system in the electrochemical corrosion tests. This due to the possible variation of the microstructural condition of the electroless nickel deposit, which initially, depending on its content of $\mathrm{P}$, could be expected to be amorphous and that the heating associated with the flame thermal spray process could modify, to some degree, towards a partial or total crystallinecondition, and as result less corrosion resistance, as stated in [16] [17] [18] [19].

In Figure 4, the system consisting of the lower layer of a NiCrFeBSi obtained

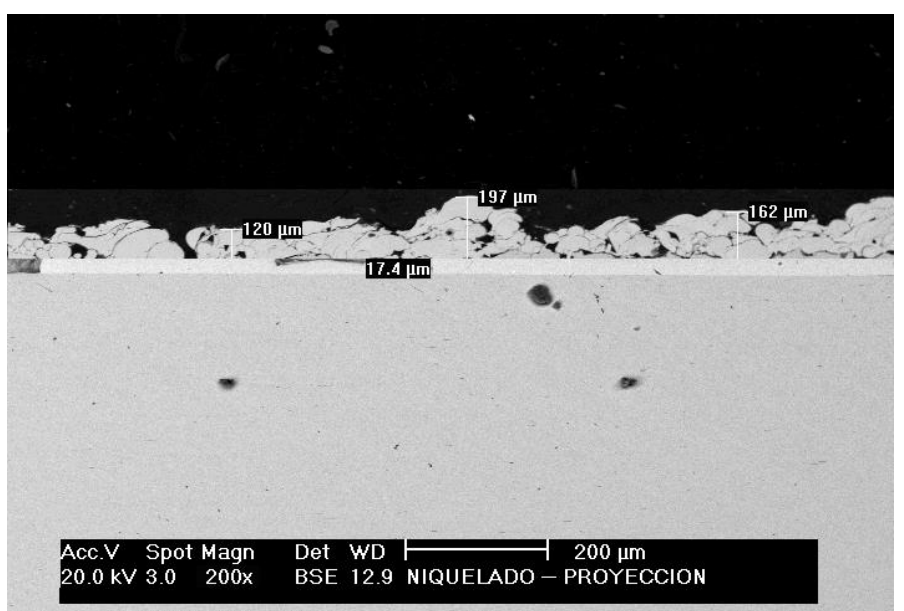

Figure 3. SEM Image of a duplex coating consisting of a deposit of electroless Ni-P and, on it, another Flame Thermal Spraying coating. Perceived are areas where NiCrBFeSi FTS coating is not observed and significant variation in thickness exist. BSE 200x.

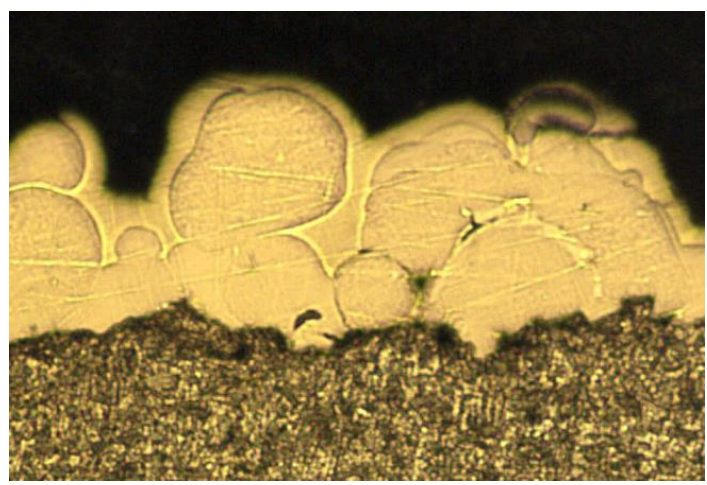

Figure 4. Optical microscope image of a system consisting of a lower layer of NiFeCrBSi flamethermal spray layer and an upper deposit of an Electroless Nickel coating. Remarkable is the hiding power of the electroless nickel deposit following the detailed outline of the lower layer. 
by flame thermal spray process can be observed. On top of this, an electroless nickel deposit is evident and perfectly covers the contour of the flame thermal spray layer, which causes a "sealing" action of the areas with porosity of this layer, a situation that can explain, to a large extent, the increase in the corrosion resistance of this duplex coating, which can be corroborated in the results of the electrochemical corrosion tests.

Figure 5 confirms that the electroless nickel deposit follows the contour of the flame thermal spray coating, thereby enabling a "sealant" action which undoubtedly is effective, resulting in a decrease in the effect of porosity and helps to reduce the risk of corrosion.

Figure 6 shows a sample of one of the spectra obtained from electroless nickel deposits in which it can be seen that in these coatings the P content is above $9 \%$ by weight, which would be in agreement with the approach that would be expected to be amorphous, and which has been reported in other works [16] [17] [18] [19].

Figure 7 shows a EDS spectrum of one of the coatings generated by flame thermal spray process of the NiCrFeBSi combination. In this spectrum, the

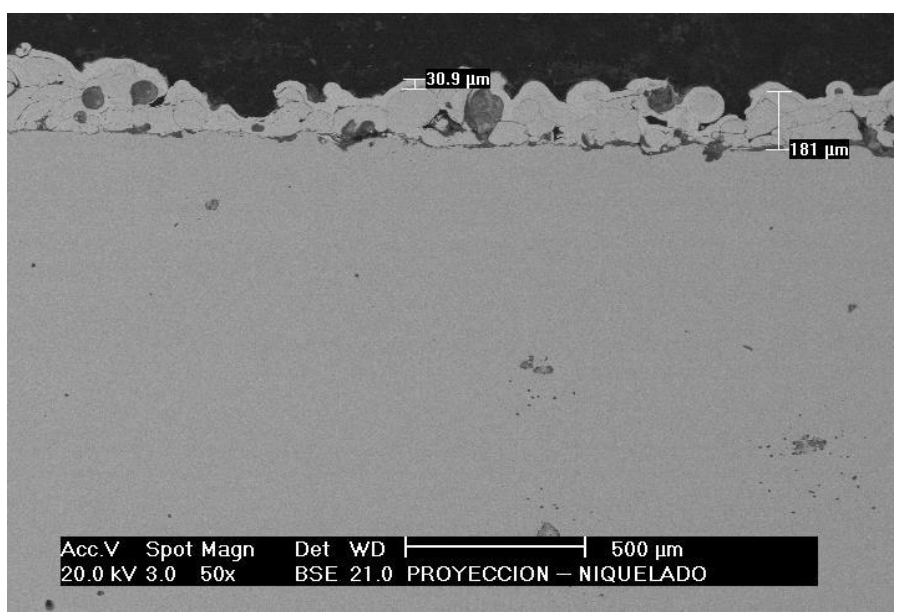

Figure 5. SEM image of a Ni-P electroless nickel deposit over a NiCrFeBSi flame thermal spray layer. The hiding capacity of the electroless nickel deposit is evident. BSE. 50×.

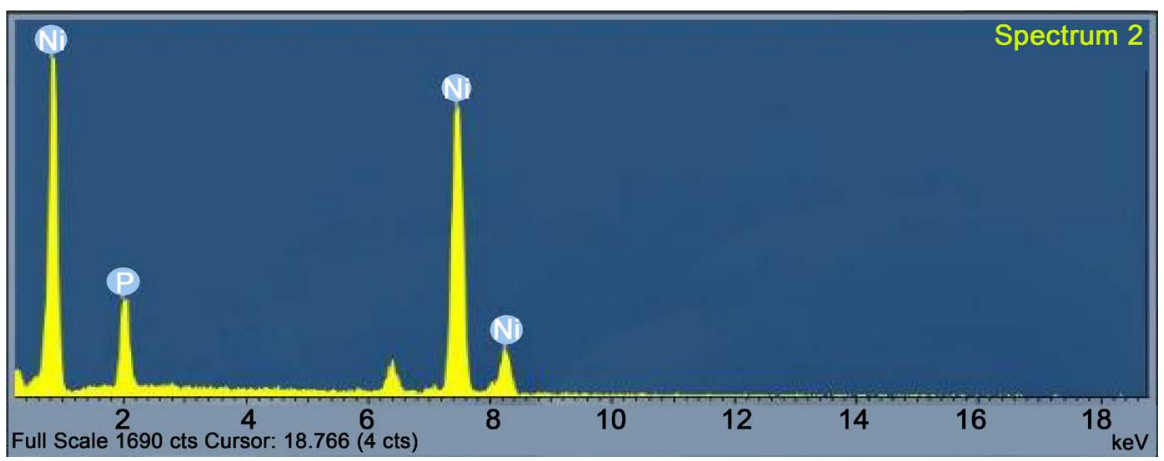

Figure 6. EDS Spectrum of an electroless nickel deposit on a low carbon steel AISI 1018 and chemical composition of the substrate and the electroless nickel coating NiP, highlighting the percentage of $\mathrm{P}$ greater than $9 \%$. 


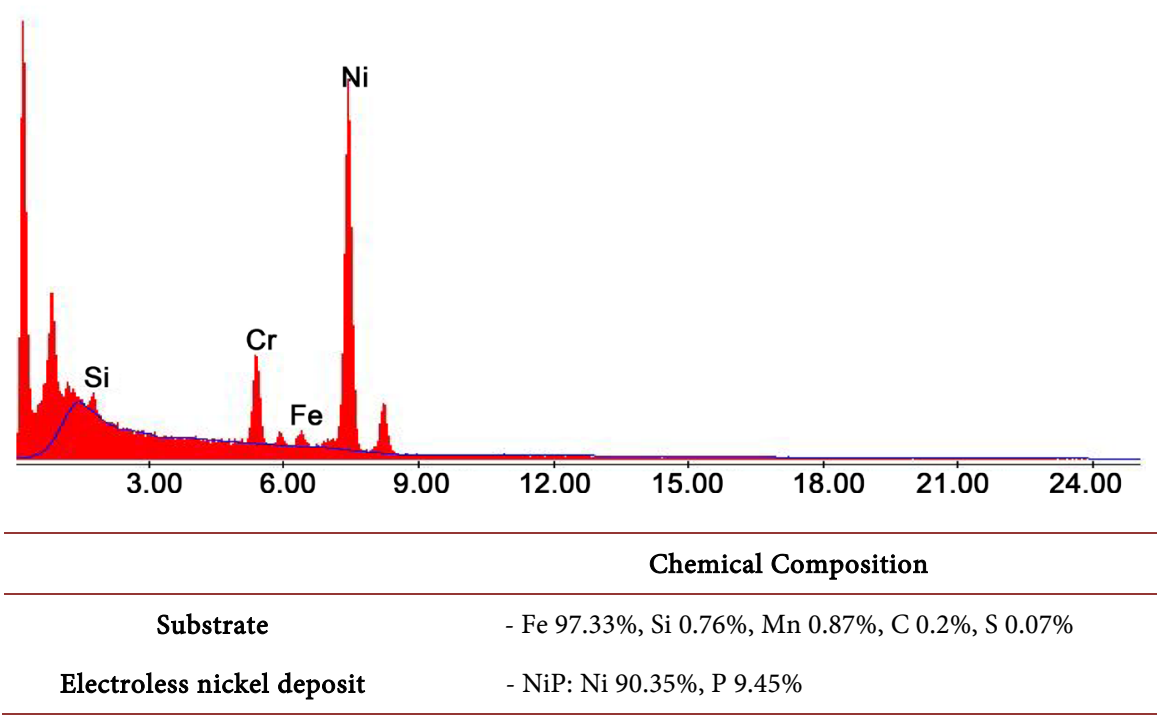

Figure 7. EDS Spectrum from the microprobe of a NiCrFeBSi coating obtained by Flame Thermal Spray process on low carbon AISI 1018 steel.

Table 2. Calculated corrosion rates of the various coating systems tested, in a solution of $\mathrm{NaCl}$ (3.5\% weight), based on Polarization Test results.

\begin{tabular}{cc}
\hline Coating & Corrosion Rate (mm/year) \\
\hline 1018 Carbon Steel (CS) & 4.36 \\
Electroless Nickel Coating on Carbon Steel (EN on CS) & 0.86 \\
Flame Thermal Spray on Carbon Steel (FTS on CS) & 2.65 \\
Flame Thermal Spray on Electroless Nickel (FTS on EN) & 1.46 \\
Electroless Nickel on Flame Thermal Spray (EN on FTS) & 0.59 \\
\hline
\end{tabular}

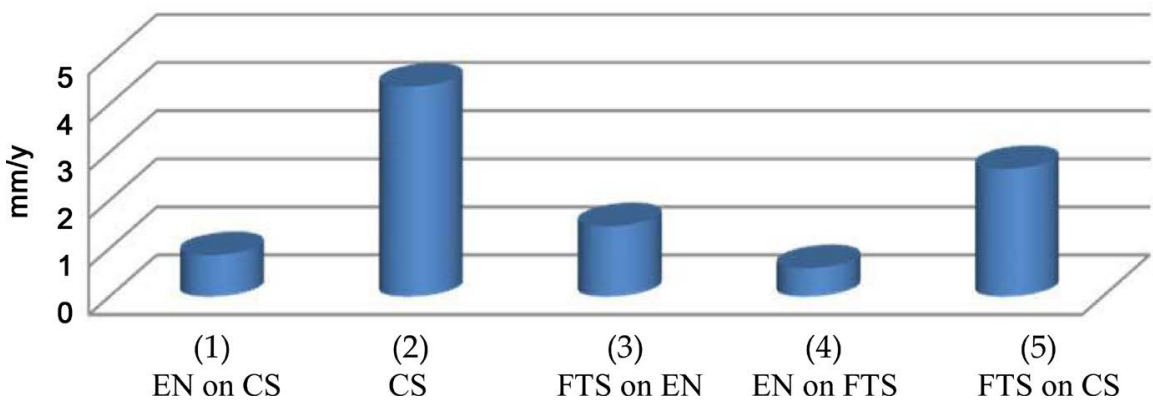

Figure 8. Graphic representation of the corrosion rate of the various systems tested and AISI 1018 steel bare.

presence of the components constituting the layer can be corroborated.

Table 2 and Figure 8, show a comparison of the corrosion rates of the various coating systems evaluated in this work and for this it is clear that either coating system has a higher corrosion resistance than low carbon steel AISI 1018 alone (4.36 mm/year). It should also be noted that of the coated parts, those coated with the NiCrFeBSi layer are the ones with the highest corrosion rate (2.65 $\mathrm{mm} /$ year), which is considered associated with the porosity of the coating. Re- 
lated to the electroless nickel plated sample, results $(0.86 \mathrm{~mm} /$ year $)$ confirm its good qualities as a corrosion resistant coating, which is linked to its predominant amorphous condition as a function of the $\mathrm{P}$ content, as reported in other studies [16] [17] [18] [19]. Corrosion rate is higher than found in other papers such as [16] in which an aluminum alloy was coated with an electroless NiP coating $(11 \% \mathrm{P})$ and evaluated by electrochemical tests in a solution such as the one used in this work, where a corrosion rate of $0.08 \mathrm{~mm} /$ year is reported. This can be associated with the higher content of $\mathrm{P}$ reported in [16], which provides a higher corrosion resistance.

In agreement with these results, [16] [17] [18] [19], indicate that amorphous electroless Ni-P (with high P content) coatings are expected to have better corrosion resistance due to the absence of grain boundaries and the possible formation of a protective layer of nickel oxide and phosphorus compound.

Works have been carried out to evaluate the corrosion resistance of Ni-P, on a composite material for wind turbine blades, with $\mathrm{P}$ content of $<7 \%$ and $>7 \%$ in a $\mathrm{NaCl}$ solution at 3.5\% weight, conclude that the best corrosion resistance is with contents of P > 7\% [20] and in this work, has a content of 9\% that coincides with those in the literature. Another work where they cover closed-cell aluminum foams with a Ni-P coating [21] indicates that there is an increase in corrosion resistance in chloride sodium solutions to $3.5 \%$ also coinciding with the content of $\mathrm{P}$ in the coating increases.

In [21], report that electroless nickel deposit containing high phosphorus content reacts with electrolyte to form a layer of adsorbed hypophosphite anions, which will block the supply chain of electrolyte the electrode surface and can help to form a passive nickel film.

The system, in which a NiCrFeBSi layer, obtained by flame thermal spray technology is placed on an electroless nickel deposit, has a higher corrosion rate $(1.46 \mathrm{~mm} /$ year) than the electroless nickel coating alone. Although it is recommended to perform a broader characterization of this system in a future work, it is considered that some possible factors that can explain this inappropriate behavior, are associated with the inhomogeneity of the flame thermal spray process layer which can collaborate to generate local cells between Ni-P and the NiCrFeBSi combination. As previously reported [16] [17] [18] [19], electroless nickel NiP coatings with $\mathrm{P}$ contents of the order of $9 \%$ (by weight) and higher tend to have a predominantly amorphous condition which can be modified by heating, causing a transition process to metastable intermediate phases (microcrystalline) in the coating, to subsequently pass into a fully crystalline condition with stable phases $\left(\mathrm{Ni}_{3} \mathrm{P}\right.$ and $\left.\mathrm{Ni}\right)$.

On the other hand, Jokinen, Korpiola and Mahiout report that the heating caused by an HVOF process generates the crystallization of an electroless nickel $\mathrm{NiP}$ deposit [22]. In agreement with this report, in the present work this modification in the microstructure of the process can explain the fact that the duplex system of a layer of electroless nickel coated by another of NiCrFeBSi produced by flame thermal spray process shows a higher corrosion rate than the duplex 
system where the electroless nickel coating (which is amorphous), is placed above the NiCrFeBSi layer produced by flame thermal spray.

Regarding the behavior of the system that presents a lower NiCrFeBSi layer obtained by flame thermal spray process with an upper electroless nickel deposit, which presents the lowest corrosion rate $(0.59 \mathrm{~mm} /$ year $)$, it is considered that characteristics such as the excellent corrosion resistance of the amorphous electroless nickel coatings [16] [17] [18] [19], the ability of this type of coatings to generate a uniform coating, regardless to the substrate geometry and the "sealing" action that this entails, is considered to support all these effects and explain the response of the duplex system which cause the increase in corrosion resistance.

Comparing this system with [23], there is evidence that despite the use of stainless steel coatings produced by High Velocity Oxygen Fuel (HVOF) thermal spray process the problem of porosity in the coating can arise and cause corrosion problems in presence of $\mathrm{NaCl}$. A more recent article [24], coincides with the present work on the utility of use of electroless nickel coatings on a layer of martensitic stainless steel produced by HVOF to overcome the limitation of the porosity of these coatings through the use of a uniform duplex electroless nickel coating. In this case, a layer of 3.5 micrometres of an electroless nickel $\mathrm{NiP}$ amorphous coating is used on an upper layer of an electroless nickel $\mathrm{NiB}$ of 36 micrometers is placed and both on a layer of martensitic stainless steel of 150 micrometers being placed. Duplex coatings system obtain improvement in corrosion resistance, associated with the electroless NiP layer and in the adhesive wear resistance, attached to the high hardness electroless nickel NiB layer. Unlike this article, in this work the duplex system uses flame thermal spray process plus electroless nickel NiP coating, which is a more economical procedure. An additional aspect to be highlighted in this article regarding [24], is the evidenceof the electroless nickel coating's ability to perfectly follow the contour of NiCrFeBSi coating produced by flame thermal spray process, which is a factor that contribute to the enhancement of the corrosion resistance.

Some additional reflections derive from these results. A first important fact is that adding an electroless nickel deposit to a layer produced by flame thermal spray technology can substantially increase the corrosion resistance of this layer. This, consequently, can open an interesting possibility to expand its applications and reduce the common problems that these coatings can present, derived from its high porosity and poor adhesion.

However, on the other hand, it is necessary to complete a more extensive characterization of these duplex systems. One of the restrictions of these proposed systems is that the electroless nickel deposit is not recommended for use at temperatures greater than $500^{\circ} \mathrm{C}$, which would suggest this kind of combinations should not be used under those conditions

\section{Conclusions}

The corrosion resistance of a $\mathrm{NiCrBFeSi}$ coating obtained by flame thermal 
spray technologies has been enhanced by adding an upper layer of a NiP electroless nickel deposit.

The corrosion resistance of an amorphous electroless nickel deposit, and the ability of this kind of coating to coat with uniform thickness and to follow the contour of the NiCrFeBSi layer generated by flame thermal spray process have contributed to this situation.

These characteristics of the duplex coating allow overcoming the limitations of low adhesion and to produce a condition of "sealing" the porosity of the coatings obtained by flame thermal spray process.

The duplex system flame thermal spray layer (NiCrFeBSi) plus Ni-P electroless nickel is a system that allows extending the possible applications of coatings generated by FTS particularly when corrosion resistance is a predominant factor for their selection.

\section{Acknowledgements}

This work was supported by UNAM-PAPIIT IT101318 "Desarrollo de Tecnologías de Superficie para la Optimización de Componentes y Sistemas". To Facultad de Ingeniería UNAM and Elvira Ostria.

\section{Conflicts of Interest}

The authors declare no conflict of interest.

\section{References}

[1] Pawloski, L. (1995) The Science and Engineering of Thermal Spray Coatings. British Library Cataloguing, London.

[2] González, R., Cadenas, M., Fernández, R., Cortizo, J.L. and Rodríguez, E. (2007) Wear Behaviour of Flame Sprayed NiCrBSi Coating Remelted by Flame or by Laser. Wear, 262, 301-307. https://doi.org/10.1016/j.wear.2006.05.009

[3] Raghu, K., Ramanaiah, N. and Sarcar, M. (2016) Corrosion Behavior of Duplex Coatings. Journal of King Saud University, Engineering Sciences, 28, 246-250. https://doi.org/10.1016/j.jksues.2014.04.006

[4] Nestler, M.C., Spies, H.J. and Herrmann, K. (1996) Production of Duplex Coatings by Thermal Spraying and Nitriding. Surface Engineering, 12, No. 4. https://doi.org/10.1179/sur.1996.12.4.229

[5] Casadei, F. and Tului, M. (2013) Combining Thermal Spraying and PVD Technologies: A New Approach of Duplex Surface Engineering for Ti Alloys. Surface and Coatings Technology, 237, 415-420. https://doi.org/10.1016/j.surfcoat.2013.08.057

[6] Barba, A. (2001) Recubrimientos por Reducción Química Autocatalítica [Electroless Nickel Coatings]. In: Vaamonde, A.J.V. and Juan, J., Eds., Ciencia e Ingeniería de la Superficie de los Materiales Metálicos, Colección de Textos Universitarios, No 31, Consejo Superior de Investigaciones Científicas de España, 261-279.

[7] Vargas, L., Barba, A., Bolarín, A. and Sánchez, F. (2006) Age Hardening of Ni-Mo-P Electroless Deposit. Surface Engineering, 22, 58-62. https://doi.org/10.1179/174329406X84976

[8] Grosjeana, A., Rezrazia, M., Takadoumb, U. and JBerc, P. (2001) Hardness, Friction and Wear Characteristics of Nickel-SiC Electroless Composite Deposits. Surface 
and Coatings Technology, 137, 92-96.

https://doi.org/10.1016/S0257-8972(00)01088-4

[9] Sánchez, F., Bolarín, A., Barba, A., Torres, G. and Hernández, L.E. (2012) Obtención y Caracterización de Recubrimientos Compuestos Ni-P-X (X = SiC y WC) [Preparation and Characterization of Composite Ni-P-X Coatings ( $\mathrm{X}=\mathrm{SiC}$ and WC)]. Surface and Vaccum, 25, 128-133.

[10] William, V., Selvi, V., Barshilia, C. and Rajam, K. (2006) Effect of Electroless Nickel Interlayer on the Electrochemical Behavior of Single Layer CrN, TiN, TiAlN Coatings and Nanolayered TiAlN/CrN Multilayer Coatings Prepared by Reactive Dc Magnetron Sputtering. Electrochimica Acta, 51, 3461-3468.

https://doi.org/10.1016/j.electacta.2005.09.042

[11] Li, J.F. and Ding, C.X. (2000) Improvement in Tribological Properties of Plasma-Sprayed $\mathrm{Cr}_{3} \mathrm{C}_{2}-\mathrm{NiCr}$ Coating Followed by Electroless Plating Ni-Based Alloy. Wear, 240, 180-185.

[12] Sankara, T.S., Krishnaveni, K. and Seshadri, S.K. (2003) Electroless Ni-P/Ni-B Duplex Coatings: Preparation and Evaluation of Microhardness, Wear and Corrosion Resistance. Material Chemistry and Physics, 82, 771-779.

[13] Bonin, L. and Vitry, V. (2016) Mechanical and Wear Characterization of Electroless Nickel Mono and Bilayers and High Boron-Mid Phosphorous Electroless Nickel Duplex Coatings. Surface and Coatings Technology Part A, 307, 957-962.

[14] Jafari, M., Enayati, M., Salehi, M., Nahvi, S. and Park, C.G. (2013) Microstructural and Mechanical Characterizations of a Novel HVOF-Sprayed WC-Co Coating Deposited from Electroless Ni-P Coated WC-12Co Powders. Materials Science \& Engineering $A, \mathbf{5 7 8}, 46-53$.

[15] Jafari, M., Enayati, M.H., Salehi, M., Nahvi, S. and MPark, C.G. (2013) Improvement in Tribological Properties of HVOF Sprayed WC-Co Coatings using Electroless Ni-P Coated Feedstock Powders. Surface and Coatings Technology, 235, 310-317.

[16] Gil, L., Jiménez, L., Castro, A.C., Puchi-Cabrera, E.S. and Staia, M.H. (2008) Evaluation of the Effect of Ni-P Coating on the Corrosion Resistance of the Aluminium 7075 T6 Alloy. Revista de Metalurgia, 44, 66-73.

[17] Keong, K., Sha, W. and Malinov, S. (2002) Crystallization and Phase Transformation Behaviour of Electroless Nickel-Phosphorous Deposits with Low and Medium Phosphorus Contents under Continuous Heating. Journal of Materials Science, 37, 4445-4450. https://doi.org/10.1023/A:1020641611389

[18] Guo, Z., Keong, K.G. and Sha, W. (2003) Crystallization and Phase Transformation Behaviour of Electroless Nickel Phosphorus Plating during Continuous Heating. Journal of Alloys and Compounds, 358, 112-119.

[19] Keong, K., Sha, W. and Malinov, S. (2002) Crystallisation Kinetics and Phase Transformation Behaviour of Electroless Nickel-Phosphorus Deposits with High Phosphorous Content. Journal of Alloys and Compounds, 334, 192-199.

[20] Lee, C.K. (2008) Corrosion and Wear-Corrosion Resistance Properties of Electroless Ni-P Coatings on GFRP Composite in Wind Turbine Blades. Surface \& Coatings Technology, 202, 4868-4874.

[21] Liu, J., Zhu, X., Sudaga, J., Gao, F. and Feng, P. (2012) Preparation and Corrosion Resistance of Electroless Ni-P Coating on Open-Cell Aluminum Foams. International Journal of Electrochemical Science, 7, 5951-5961.

[22] Jokinen, Korpiola, K. and Mahiout, A. (2000) Duplex Coating of Electroless Nickel 
and HVOF (High-Velocity Oxygen Fuel) Sprayed WC-Co. Journal of Thermal, Spray Technology, 9, 241-244. https://doi.org/10.1361/105996300770349980

[23] Suegama, P., Fugivara, C., Benedetti, A., Fernández, J., Delgado, J. and Guilemany, J. (2005) Electrochemical Behavior of Thermally Sprayed Stainless Steel Coatings in $3.4 \% \mathrm{NaCl}$ Solution. Corrosion Science, 47, 605-620.

[24] Mindivan, F. and Mindivan, H. (2017) The Study of Electroless NiB/NiP Duplex Coating on HVOF Sprayed Martensitic Stainless Steel Coating. Acta Physica Polonica $A, 131,64-67$. 